\title{
Fuzzy Pre Generalized Pre Regular Weakly Homeomorphism in Fuzzy Topological Spaces
}

Vivekananda Dembre

Assistant-Professor

Department of Mathematics,

Sanjay Ghodawat University, Kolhapur, India.
Sandeep.N.Patil

Assistant Professor,

Department of Civil Engineering,

Sanjay Ghodawat Polytechnic, Kolhapur,India

\begin{abstract}
In this paper we introduce and study two new fuzzy homeomorphisms,namely fuzzy pgprw-homeomorphism and fuzzy pgprw-closed homeomorphism. We prove that every fuzzy homeomorphism is fuzzy pgprw-homeomorphism and we prove that the composition of two fuzzy pgprw closed homeomorphism is a pgprw-homeomorphism.
\end{abstract}

Keywords: fuzzy pgprw-homeomorphism, fuzzy pgprw-closed set, fuzzy pgprw-open set.

\section{INTRODUCTION}

The concept of a fuzzy subset was introduced and studied by L.A.Zadeh in the year 1965. The subsequent research activities in this area and related areas have found applications in many branches of science and engineering. In the year 1965, L.A.Zadeh [1] introduced the concept of fuzzy subset as a generalization of that of an ordinary subset. The introduction of fuzzy subsets paved the way for rapid research work in many areas of mathematical science. In the year 1968, C.L.Chang [2] introduced the concept of fuzzy topological spaces as an application of fuzzy sets to topological spaces . Subsequently several researchers contributed to the development of the theory and applications of fuzzy topology. The theory of fuzzy topological spaces can be regarded as a generalization theory of topological spaces. An ordinary subset $\mathrm{A}$ or a set $\mathrm{X}$ can be characterized by a function called characteristic function

$$
\begin{aligned}
& \mu_{\mathrm{A}}: \mathrm{X} \rightarrow[0,1] \text { of } \mathrm{A}, \text { defined by } \\
& \mu_{\mathrm{A}}(\mathrm{x})=1, \quad \text { if } \mathrm{x} \in \mathrm{A} . \\
&=0, \quad \text { if } \mathrm{x} \in \mid \mathrm{A} .
\end{aligned}
$$

Thus an element $\mathrm{x} \in \mathrm{X}$ is in $\mathrm{A}$ if $\mu_{\mathrm{A}}(\mathrm{x})=1$ and is not in $\mathrm{A}$ if $\mu_{\mathrm{A}}(\mathrm{x})=0$. In general if $\mathrm{X}$ is a set and $\mathrm{A}$ is a subset of $\mathrm{X}$ then $\mathrm{A}$ has the following representation. $\mathrm{A}=\left\{\left(\mathrm{x}, \mu_{\mathrm{A}}\right.\right.$ (x)): $\mathrm{x} \in \mathrm{X}\}$, here $\mu_{\mathrm{A}}$ (x) may be regarded as the degree of belongingness of $\mathrm{x}$ to $\mathrm{A}$, which is either 0 or 1 .

Hence $\mathrm{A}$ is the class of objects with degree of belongingness either 0 or 1 only. Prof. L.A.Zadeh [1] introduced a class of objects with continuous grades of belongingness ranging between 0 and 1 ; he called such a class as fuzzy subset. A fuzzy subset $\mathrm{A}$ in $\mathrm{X}$ is characterized as a membership function $\mu_{\mathrm{A}}: \mathrm{X} \longrightarrow[0,1]$, which associates with each point in $\mathrm{x}$ a real number $\mu_{\mathrm{A}}(\mathrm{x})$ between 0 and 1 which represents the degree or grade membership of belongingness of $\mathrm{x}$ to A.

The purpose of this paper is to introduce a new class of fuzzy sets called fuzzy pgprw-closed sets in fuzzy topological spaces and investigate certain basic properties of these fuzzy sets. Among many other results it is observed that every fuzzy closed set is fuzzy pgprw-closed but conversely.Also we introduce fuzzy pgprw-open sets in fuzzy topological spaces and study some of their properties.

\section{PRELIMINARIES}

1.1Definition:[1]A fuzzy subset $A$ in a set $X$ is a function $A$ : $X \rightarrow[0,1]$. A fuzzy subset in $X$ is empty iff its membership function is identically 0 on $\mathrm{X}$ and is denoted by 0 or $\mu_{\phi}$. The set $\mathrm{X}$ can be considered as a fuzzy subset of $\mathrm{X}$ whose membership function is identically 1 on $X$ and is denoted by $\mu_{\mathrm{x}}$ or $\mathrm{I}_{\mathrm{x}}$. In fact every subset of $\mathrm{X}$ is a fuzzy subset of $\mathrm{X}$ but not conversely. Hence the concept of a fuzzy subset is a generalization of the concept of a subset.

1.2 Defnition :[1] If $A$ and $B$ are any two fuzzy subsets of a set $X$, then $A$ is said to be included in $B$ or $A$ is contained in $B$ iff $\mathrm{A}(\mathrm{x}) \leq \mathrm{B}(\mathrm{x})$ for all $\mathrm{x}$ in $\mathrm{X}$. Equivalently, $\mathrm{A} \leq \mathrm{B}$ iff $\mathrm{A}(\mathrm{x}) \leq$ $\mathrm{B}(\mathrm{x})$ for all $\mathrm{x}$ in $\mathrm{X}$.

1.3 Defnition: [1]Two fuzzy subsets $A$ and $B$ are said to be equal if $A(x)=B(x)$ for every $x$ in $X$.

Equivalently $\mathrm{A}=\mathrm{B}$ if $\mathrm{A}(\mathrm{x})=\mathrm{B}(\mathrm{x})$ for every $\mathrm{x}$ in $\mathrm{X}$.

1.4Defnition:[1] The complement of a fuzzy subset $A$ in a set $\mathrm{X}$, denoted by $\mathrm{A}^{\prime}$ or $1-\mathrm{A}$, is the fuzzy subset of $\mathrm{X}$ defined by $\mathrm{A}^{\prime}(\mathrm{x})=1-\mathrm{A}(\mathrm{x})$ for all $\mathrm{x}$ in $\mathrm{X}$. Note that $\left(\mathrm{A}^{\prime}\right)^{\prime}=\mathrm{A}$.

1.5 Defnition:[1] The union of two fuzzy subsets A and B in $\mathrm{X}$, denoted by $\mathrm{A} \vee \mathrm{B}$, is a fuzzy subset in $\mathrm{X}$ defined by (A $\vee$ $\mathrm{B})(\mathrm{x})=\operatorname{Max}\left\{\mu_{\mathrm{A}}(\mathrm{x}), \mu_{\mathrm{B}}(\mathrm{X})\right\}$ for all $\mathrm{x}$ in $\mathrm{X}$. 
1.6 Defnition:[1]The intersection of two fuzzy subsets A and $\mathrm{X}$ is 'Crisp' if it takes only the values 0 and 1 on $\mathrm{X}$.

1.7 Defnition:[1] A fuzzy set on $X$ is 'Crisp' if it takes only the values 0 and 1 on $X$.

1.8 Defnition:[2]Let $X$ be a set and be a family of fuzzy subsets of $(X, \tau)$ is called a fuzzy topology on $\mathrm{X}$ iff $\tau$ satisfies the following conditions.

(i) $\mu_{\phi} ; \mu_{\mathrm{X}} \in \tau$ : That is 0 and $1 \in \tau$

(ii) If $G_{i} \in \tau$ for $i \in I$ then $\vee G_{i} \in \tau$

$$
i \in I
$$

\section{(iii) If $\mathrm{G}, \mathrm{H} \in \tau$ then $\mathrm{G} \wedge \mathrm{H} \in \boldsymbol{\tau}$}

The pair $(\mathrm{X}, \tau)$ is called a fuzzy topological space (abbreviated as fts). The members of $\tau$ are called fuzzy open sets and a fuzzy set $\mathrm{A}$ in $\mathrm{X}$ is said to be closed iff $1-\mathrm{A}$ is an fuzzy open set in X.

1.9 Remark :[2] Every topological space is a fuzzy topological space but not conversely.

1.10 Defnition:[2]Let $X$ be a fts and $A$ be a fuzzy subset in $X$. Then $\wedge\{\mathrm{B}: \mathrm{B}$ is a closed fuzzy set in $\mathrm{X}$ and $\mathrm{B} \geq \mathrm{A}\}$ is called the closure of $\mathrm{A}$ and is denoted by $\mathrm{A}$ or $\operatorname{cl}(\mathrm{A})$.

1.11 Defnition:[2]Let $A$ and $B$ be two fuzzy sets in a fuzzy topological space $(\mathrm{X}, \tau)$ and let $\mathrm{A} \geq \mathrm{B}$. Then $\mathrm{B}$ is called an interior fuzzy set of $A$ if there exists $G \in \tau$ such that $A \geq G \geq$ $B$, the least upper bound of all interior fuzzy sets of $A$ is called the interior of $\mathrm{A}$ and is denoted by $\mathrm{A}^{0}$.

1.12 Definition[3] A fuzzy set A in a fts $X$ is said to be fuzzy semiopen if and only if there exists a fuzzy open set $\mathrm{V}$ in $\mathrm{X}$ such that $\mathrm{V} \leq \mathrm{A} \leq \mathrm{cl}(\mathrm{V})$.

1.13 Definition[3] A fuzzy set A in a fts $X$ is said to be fuzzy semi-closed if and only if there exists a fuzzy closed set $\mathrm{V}$ in $\mathrm{X}$ such that $\operatorname{int}(\mathrm{V}) \leq \mathrm{A} \leq \mathrm{V}$. It is seen that a fuzzy set $\mathrm{A}$ is fuzzy semiopen if and only if 1-A is a fuzzy semi-closed.

1.14 Theorem:[3] The following are equivalent:

(a) $\mu$ is a fuzzy semiclosed set,

(b) $\mu^{\mathrm{C}}$ is a fuzzy semiopen set,

(c) $\operatorname{int}(\operatorname{cl}(\mu)) \leq \mu$.

(b) $\operatorname{int}(\operatorname{cl}(\mu)) \geq \mu^{\mathrm{c}}$
1.15 Theorem [3] Any union of fuzzy semiopen sets is a fuzzy semiopen set and (b) any intersection of fuzzy semi closed sets is a fuzzy semi closed.

\subsection{Remark[3]}

(i) Every fuzzy open set is a fuzzy semiopen but not conversely.

(ii) Every fuzzy closed set is a fuzzy semi-closed set but not conversely.

(iii) The closure of a fuzzy open set is fuzzy semiopen set

(iv) The interior of a fuzzy closed set is fuzzy semi-closed set

1.17Definition:[3] A fuzzy set $\mu$ of a $\mathrm{fts} \mathrm{X}$ is called a fuzzy regular open set of $\mathrm{X}$ if $\operatorname{int}(\operatorname{cl}(\mu)=\mu$.

1.18 Definition:[3] A fuzzy set $\mu$ of fts $\mathrm{X}$ is called a fuzzy regular closed set of $\mathrm{X}$ if $\operatorname{cl}(\operatorname{int}(\mu))=\mu$.

1.19 Theorem:[3] A fuzzy set $\mu$ of a $\mathrm{fts} \mathrm{X}$ is a fuzzy regular open if and only if $\mu^{\mathrm{C}}$ fuzzy regular closed set.

\subsection{Remark:[3]}

(i) Every fuzzy regular open set is a fuzzy open set but not conversely.

(ii) Every fuzzy regular closed set is a fuzzy closed set but not conversely.

1.21 Theorem:[3]

(i) The closure of a fuzzy open set is a fuzzy regularclosed.

(ii) The interior of a fuzzy closed set is a fuzzy regular open set.

1.22 Definition:[4] A fuzzy set $\alpha$ in fts $\mathrm{X}$ is called fuzzy rw closed if $\operatorname{cl}(\alpha) \leq \mu$ whenever $\alpha \leq \mu$ and $\mu$ is regular semi-open in X.

1.23 Definition [5]: A fuzzy set $\alpha$ in fts $\mathrm{X}$ is called fuzzy pgprw closed if $\operatorname{p-cl}(\alpha) \leq \mu$ whenever $\alpha \leq \mu$ and $\mu$ is $\operatorname{rg} \alpha$-open set in X.

1.24 Defintion [5]:A fuzzy set $\alpha$ of a fts $\mathrm{X}$ is fuzzy pgprwopen set, if it's complement $\alpha^{\mathrm{c}}$ is a fuzzy pgprw-closed in fts $\mathrm{X}$.

1.25 Defintion[6]: Let $\mathrm{X}$ and $\mathrm{Y}$ be two fts. A map 
f: $(\mathrm{X}, \mathrm{T})$ $(\mathrm{Y}, \mathrm{T})$ is called fuzzy pgprw-open map if the inverse image of every fuzzy open set in $\mathrm{X}$ is fuzzy pgprwopen in $\mathrm{Y}$.

1.26 Defintion[6]: Let $X$ and $Y$ be two fuzzy topological spaces. A map f: $(\mathrm{X}, \mathrm{T}) \rightarrow(\mathrm{Y}, \mathrm{T})$ is called fuzzy pgprwclosed map if the image of every fuzzy closed set in $\mathrm{X}$ is a fuzzy pgprw closed set in Y.

1.27 Definition[7]:Let $\mathrm{X}$ and $\mathrm{Y}$ be $\mathrm{fts}$. A map $\mathrm{f}: \mathrm{X} \rightarrow \mathrm{Y}$ is said to be fuzzy pgprw-continuous if the inverse image of every fuzzy open set in $\mathrm{Y}$ is fu

1.28 Definition[7]: Let $\mathrm{X}$ and $\mathrm{Y}$ be $\mathrm{fts}$. A map $\mathrm{f}: \mathrm{X} \rightarrow \mathrm{Y}$ is said to be a fuzzy pgprw-irresoulute map if the inverse image of every fuzzy pgprw-open in $\mathrm{Y}$ is a fuzzy pgprw-open set in $\mathrm{X}$.

1.29 definition [2]: Let $\mathrm{X}$ and $\mathrm{Y}$ be fts. A map $\mathrm{f}: \mathrm{X} \rightarrow \mathrm{Y}$ is said to be a fuzzy continuous mapping if $\mathrm{f}^{-1}(\mu)$ is fuzzy open in $\mathrm{X}$ for each fuzzy open set $\mu$ in $\mathrm{Y}$.

1.30 Definition [8]: Let $\mathrm{X}$ and $\mathrm{Y}$ be fts. A map f: $\mathrm{X} \rightarrow \mathrm{Y}$ is said to be a fuzzy -irresoulute map if the inverse image of every fuzzy semi-open in $\mathrm{Y}$ is a fuzzy semi-open set in $\mathrm{X}$.

1.31 Definition [9]: Let $X$ and $Y$ be fts. A bijection $f: X \rightarrow Y$ is said to be a fuzzy-homeomorphism Iff $\mathrm{f}$ and $\mathrm{f}^{-1}$ are fuzzy continuous.

\section{Fuzzy pgprw-homeomorphism in fuzzy topological spaces.}

Definition 2.1: Let $\mathrm{X}$ and $\mathrm{Y}$ be fts. A bijective map

$\mathrm{f}:\left(\mathrm{X}, \mathrm{T}_{1}\right) \rightarrow\left(\mathrm{Y}, \mathrm{T}_{2}\right)$ is called fuzzy pgprw-homeomorphism if $f$ and $f^{-1}$ are fuzzy pgprw-continuous map.

The family of all fuzzy pgprw-homeomorphism from (X,T) on to itself is denoted by fuzzy pgprw-Homeomorphism $(\mathrm{X}, \mathrm{T})$.

Theorem 2.2: Every fuzzy homeomorphism is fuzzy pgprwhomeomorphism.

Proof: Let a map f:(X, $\left.\mathrm{T}_{1}\right) \rightarrow\left(\mathrm{Y}_{1} \mathrm{~T}_{2}\right)$ be a fuzzy homeomorphism. Then $\mathrm{f}$ and $\mathrm{f}^{-1}$ are fuzzy continuous map. Since every fuzzy continuous map is fuzzy pgprw-continuous map $\mathrm{f}$ and $\mathrm{f}^{-1}$ are fuzzy pgprw-continuous map therefore $\mathrm{f}$ is fuzzy a pgprw-homeomorphism.

The converse of the above theorem need not be true as seen from the following example.

Example 2.3:Let $\mathrm{X}=\mathrm{Y}=\{\mathrm{a}, \mathrm{b}, \mathrm{c}, \mathrm{d}\}$ and the functions $\alpha, \beta$, $\gamma, \delta: \mathrm{X} \rightarrow[0,1]$ be defined as

$\alpha(\mathrm{x})=1 \quad$ if $\mathrm{x}=\mathrm{a}$
0 otherwise

$\beta(\mathrm{x})=1 \quad$ if $\mathrm{x}=\mathrm{b}$

0 otherwise

$\delta(\mathrm{x})=1 \quad$ if $\mathrm{x}=\mathrm{a}, \mathrm{b}, \mathrm{c}$

0 otherwise.

Consider $\mathrm{T}_{1}=\{0,1, \alpha, \beta, \gamma, \delta\}$ and $\mathrm{T}_{2}=\{0,1, \alpha, \beta, \gamma, \delta\}$ then $\left(\mathrm{X}, \mathrm{T}_{1}\right)$ and $\left(\mathrm{Y}, \mathrm{T}_{2}\right)$ are $\mathrm{fts}$.Define a map $\mathrm{f}:\left(\mathrm{X}, \mathrm{T}_{1}\right)$ $\left(Y, T_{2}\right)$ by $f(a)=c, f(b)=a, f(c)=b, f(d)=d$ then $f$ is fuzzy pgprwhomeomorphism but it is not fuzzy homeomorphism,as the image of closed set $\gamma$ in $\mathrm{X}$ is not fuzzy closed set in $\left(\mathrm{Y}, \mathrm{T}_{2}\right)$.

Theorem 2.4: Let $\mathrm{X}$ and $\mathrm{Y}$ be fuzzy topological spaces and $\mathrm{f}$ : $\left(\mathrm{X}, \mathrm{T}_{1}\right) \rightarrow\left(\mathrm{Y}, \mathrm{T}_{2}\right)$ be a bijective map.

Then the following statements are equivalent.

(a) $\mathrm{f}^{-1}$ is fuzzy pgprw continuous map.

(b) $\mathrm{f}$ is fuzzy pgprw-open map.

(c) $\mathrm{f}$ is fuzzy pgprw-closed map.

Proof: (a) implies (b) Let $\alpha$ be any fuzzy open set in X.Since $\mathrm{f}^{-1}$ is fuzzy pgprw continuous map, $\left(\mathrm{f}^{-1)-1}(\alpha)=\mathrm{f}((\alpha)\right.$ is fuzzy pgprw-open in Y. Hence $\mathrm{f}$ is fuzzy pgprw-open map.

(b)implies(c) Let $\alpha$ be any fuzzy closed set in X. Then 1- $\alpha$ is fuzzy pgprw-open in $\mathrm{x}$.Since $\mathrm{f}$ is a fuzzy pgprw-open, $\mathrm{f}(1-$ $\alpha$ ) is fuzzy pgprw-open in Y.but $\mathrm{f}(1-\alpha)=1-\mathrm{f}(\alpha)$, as $\mathrm{f}$ is a bijective map. Hence $f(\alpha)$ is fuzzy pgprw set in Y.Therefore $\mathrm{f}$ is fuzzy pgprw-closed map.

(c) implies (a) Let $\alpha$ be any fuzzy closed set in X. Then $\mathrm{f}(\alpha)$ is a fuzzy pgprw closed set in $\mathrm{Y}$ but $\left(\mathrm{f}^{-1}\right)^{-1}(\alpha)=\mathrm{f}(\alpha)$. Therefore $\mathrm{f}^{-1}$ fuzzy pgprw-continuous map.

Theorem 2.5: Let $\mathrm{X}$ and $\mathrm{Y}$ be fuzzy topological spaces and $\mathrm{f}$ : $\left(\mathrm{X}, \mathrm{T}_{1}\right) \rightarrow\left(\mathrm{Y}_{2} \mathrm{~T}_{2}\right)$ be a bijective and fuzzy pgprw-continuous map.Then the following statements are equivalent.

(a) $\mathrm{f}$ is fuzzy pgprw open map.

(b) $\mathrm{f}$ is fuzzy pgprw-homeomorphism.

(c) $\mathrm{f}$ is fuzzy pgprw-closed map.

Proof: (a) implies (b) by hypothesis and assumption $\mathrm{f}$ is a fuzzy pgprw-homeomorphism 
(b) implies (c) since $\mathrm{f}$ is fuzzy pgprw-homeomorphism, it is fuzzy pgprw-open,so by the above theorem 2.4 it is a fuzzy pgprw-closed map.

(c) implies (b) Let $\sigma$ be any fuzzy open set in X. so that 1-

$\sigma$ is a closed set and f being pgprw-closed,f( $1-\sigma)$ is fuzzy pgprw-closed in Y.but $\mathrm{f}(1-\alpha)=1-\mathrm{f}(\sigma)$, thus $\mathrm{f}(\sigma)$ is fuzzy pgprw open set in Y.Therefore $f$ is fuzzy pgprwopen map.

Defintion 2.6 : A bijective map $\mathrm{f}:\left(\mathrm{X}, \mathrm{T}_{1}\right) \rightarrow\left(\mathrm{Y}, \mathrm{T}_{2}\right)$ is called a fuzzy pgprw-closed homeomorphism. If $\mathrm{f}_{\text {and }} \mathrm{f}^{-1}$ are fuzzy pgprw-irresolute map. We say that spaces $\left(\mathrm{X}, \mathrm{T}_{1}\right)$ and $\left(\mathrm{Y}, \mathrm{T}_{2}\right)$ are fuzzy pgprw closed homeomorphism if there exist a fuzzy pgprw-closed homomorphism from $\left(\mathrm{X}, \mathrm{T}_{1}\right)$ onto $\left(\mathrm{Y}, \mathrm{T}_{2}\right)$.

The family of all fuzzy pgprw-homeomorphism from (X,T) onto itself is denoted by fpgprw-h(X,T).

Theorem 2.7: Every fuzzy pgprw closed homeomorphism is fuzzy pgprw-homeomorphism but not conversely.

Proof: The proof follows from the fact that every fuzzy pgprw-irresolute map is fuzzy pgprw-continuous map but not conversely.

Theorem 2.8: Let $\left(\mathrm{X}, \mathrm{T}_{1}\right),\left(\mathrm{Y}, \mathrm{T}_{2}\right) \&\left(\mathrm{Z}, \mathrm{T}_{3}\right)$ be a fts and $\mathrm{f}:\left(\mathrm{X}, \mathrm{T}_{1}\right) \rightarrow\left(\mathrm{Y}, \mathrm{T}_{2}\right), \mathrm{g}:\left(\mathrm{Y}, \mathrm{T}_{2}\right) \rightarrow\left(\mathrm{Z}, \mathrm{T}_{3}\right)$ be fuzzy Pgprwhomeomorphism. Then their composition gof: $\left(\mathrm{X}, \mathrm{T}_{1}\right) \rightarrow\left(\mathrm{Z}, \mathrm{T}_{3}\right)$ is a fuzzy is a fuzzy pgprw-closed homeomorphism.

Proof: Let $\mu$ be a fuzzy pgprw-open set in (Z,T3), Since g is a fuzzy pgprw-irresolute map, $\mathrm{g}^{-1}(\mu)$ is a fuzzy pgprw-open set in $\left(\mathrm{Y}, \mathrm{T}_{2}\right)$. Since $\mathrm{f}$ is a fuzzy pgprw-irreolute map, $\mathrm{f}^{-1}\left(\mathrm{~g}^{-1}(\mu)\right.$ is a fuzzy pgprw-open set in $\left(\mathrm{X}, \mathrm{T}_{1}\right)$ but $\mathrm{f}^{-1}\left(\mathrm{~g}^{-1}(\mu)==(\text { gof })^{-1}\right.$ $=(\text { gof })^{-1}(\mu)$. Therefore (gof) is fuzzy pgprw-irresolute map.

To prove: (gof) ${ }^{-1}$ is fuzzy pgprw-iresolute map. Let $\alpha$ be a fuzzy pgprw-open set in $\left(\mathrm{X}, \mathrm{T}_{1}\right)$. Since $\mathrm{f}^{-1}$ is fuzzy pgprwirresolute map, $\left(\mathrm{f}^{-1}\right)^{-1}(\alpha)$ is a fuzzy pgprw -open set in $\left(\mathrm{Y}, \mathrm{T}_{2}\right)$ also $\left(\mathrm{f}^{-1}\right)^{-1}(\alpha)=\mathrm{f}(\alpha)$. Since $\mathrm{g}^{-1}$ is fuzzy pgprw-irresolute map, $\left(\left(\mathrm{g}^{-1}\right)^{-1}\right)\left(\mathrm{f}(\alpha)\right.$ is a fuzzy pgprw-open set in $\left(\mathrm{Z}, \mathrm{T}_{3}\right)$ that is $\left(\left(\mathrm{g}^{-1}\right)^{-1}\right)(\mathrm{f}(\alpha))=\mathrm{g}(\mathrm{f}(\alpha))=(\mathrm{gof})(\alpha)=\left((\mathrm{gof})^{-1}\right)^{-1}(\alpha)$. Therefore (gof) $^{-1}$ is fuzzy pgprw-irresolute map.Thus gof and (gof) ${ }^{-1}$ are fuzzy pgprw-irresolute map. Hence gof is fuzzy pgprw-closed homeomorphism.

Theorem 2.9: The set fuzzy pgprw-closed homeomorphism $(\mathrm{X}, \mathrm{T})$ is a group under the composition map.

Proof: Define a binary operation* f-pgprw closed homeomorphism $(\mathrm{X}, \mathrm{T}) \times \mathrm{f}$-pgprw closed homeomorphism $(\mathrm{X}, \mathrm{T}) \rightarrow \mathrm{f}$ pgprwc-h $(\mathrm{X}, \mathrm{T})$ by $\mathrm{By} \mathrm{f}^{*} \mathrm{~g}=$ gof for all $\mathrm{f}, \mathrm{g} \in \mathrm{f}$ $\operatorname{pgprwc}-\mathrm{h}(\mathrm{X}, \mathrm{T})$ and $\mathrm{o}$ is the usual operation of composition of maps. Then by theorem 2.8, gof $\in$ f pgprw closed $h(X, T)$ we know that, the composition of maps is associate and the identity map I: $(\mathrm{X}, \mathrm{T}) \quad(\mathrm{X}, \mathrm{T})$ belonging to fuzzy pgprw closed-h(X,T) serves as the identity element. If $\mathrm{f} \in \mathrm{fpgprw}$ closed-h(X,T)then $\mathrm{f}^{-1} \in$ fpgprw closed-h(X,T) s.t fof ${ }^{-1}=\mathrm{f}^{-}$ ${ }^{1} \mathrm{of}=\mathrm{I}$ and so inverse exist for each element of $\mathrm{f}$ pgprw-c$h(X, T)$, Therefore [ f pgprw-c-h(X,T),o] is a group under the operation of composition of maps.

Theorem 2.10: Let $\mathrm{f}:\left(\mathrm{X}, \mathrm{T}_{1}\right) \rightarrow\left(\mathrm{Y}, \mathrm{T}_{2}\right)$ be a fuzzy pgprwclosed homeomorphism then $\mathrm{f}$ induces an isomorphism from the group fuzzy pgprw closed $h\left(X, T_{1}\right)$ on to the group $f$ $\operatorname{pgprw}-\mathrm{h}\left(\mathrm{Y}, \mathrm{T}_{2}\right)$.

Proof: Using the map f, we define a map $\mu_{\mathrm{f}}$ : f pgprw closed$\mathrm{h}\left(\mathrm{X}, \mathrm{T}_{1}\right) \rightarrow \mathrm{f}$-pgprwclosed-h(Y,T$)$ by $\mu_{\mathrm{f}}(\mathrm{h})=$ fohof $^{-1}$ for every $\mathrm{h} \in$ fuzzy pgprw closed-h $\left(\mathrm{X}, \mathrm{T}_{1}\right)$. Then $\mu_{\mathrm{f}}$ is a bijection. Further

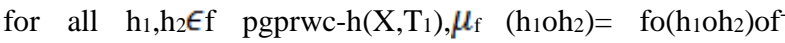
${ }^{1}=\left(\right.$ foh $_{1}$ of $\left.{ }^{-1}\right) \mathrm{o}\left(\right.$ foh $_{2}$ of $\left.{ }^{-1}\right)=\mu_{\mathrm{f}}\left(\mathrm{h}_{1}\right) \mathrm{o} \mu_{\mathrm{f}}\left(\mathrm{h}_{2}\right)$. Therefore $\mu_{\mathrm{f}}$ is a homeomorphism and so it is an isomorphism induced by $\mathrm{f}$.

\section{References:}

[1] L.A.Zadeh, Fuzzy sets, Information and control, 8 (1965) 338-353.

[2]C.L.Chang, Fuzzy topological spaces, JI. Math. Anal. Appl., 24(1968), 182-190.

[3] K.K.Azad, On fuzzy semi continuity, fuzzy almost continuity and

fuzzy weakly continuity. JI. Math. Anal. Appl. 82 No. 1 (1981), 14-32.

[4] S. S. Benchalli, R. S. Wali and Basavaraj M. Ittanagi on fuzzy rw-closed sets and fuzzy rw-open sets in fuzzy topological spaces Int. J. of Mathematical Sciences and Applications,Vol. 1, No. 2, May 2011.

[5] R.S.Wali and Vivekananda Dembre,R.S.Wali and Vivekananda Dembre,Fuzzy pgprw-closed sets and Fuzzy pgprw-open sets in Topological SpacesVolume 3, No. 3, March 2016 Journal of Global Research in Mathematical Archives.

[6] R.S.Wali and Vivekananda Dembre,Fuzzy pgprw-open maps and fuzzy pgprw-closed maps in fuzzy topological spaces; International Journal of Statistics and Applied Mathematics 2016; 1(1): 01-07 
International Journal of Computer Applications Technology and Research

Volume 7-Issue 02, 28-34, 2018, ISSN:-2319-8656

[7] R.S.Wali and Vivekananda Dembre,Fuzzy pgprwcontinuous maps and fuzzy pgprw-irresolute in fuzzy topological spaces; International Journal of Statistics and Applied Mathematics 2016; 1(1): 01-07

[8] Mukerjee,M.N. and Sinha ,s.p,irresolute and almost open function between fts,fuzzy sets and systems,29(1989),141148.

[9]Ferraro,M and Foster, D.H.differention of fuzzy continuous mappings on fts,jour. Math.anal \&appl 121(1987),1-7.

[10]Thakur S.S. and Bajpai Pandey Jyoti "Intuitionistic Fuzzy $\operatorname{rg} \alpha$-closed sets", International Journal of Fuzzy system and Rough System 4(1), 67-73.

[11] R.S.Wali and Vivekananda Dembre; On Pre Generalızed Pre Regular Weakly Closed Sets in Topological Spaces
;Journal of Computer and Mathematical Sciences, Vol.6(2),113-125, February 2015. 